\title{
The Plastic Cycle - An Unknown Branch of the Carbon Cycle
}

\author{
Xia Zhu* \\ Department of Physical and Environmental Sciences, University of Toronto Scarborough, Toronto, ON, Canada
}

Keywords: plastic, biogeochemical cycles, carbon cycle, climate change, environmental transport, marine debris, environmental pollution, mass balance

As early as the 1970s, plastic pollution has been reported in the environment (Carpenter and Smith, 1972). Then in the late 1990s, a sea captain discovered large amounts of plastic accumulating in the North Pacific Gyre (Moore et al., 2001), which is referred to as the "North Pacific Garbage Patch." Now in 2020, plastic pollution is ubiquitous in the environment-from remote mountain lakes (Free et al., 2014) to the deep abyss of the ocean (Jamieson et al., 2019) to the very air we breathe (Liu et al., 2019; Brahney et al., 2020). It is clear that plastic pollution has become a major environmental issue of our time. Due to the low degradation rates of plastic, almost every piece of plastic that is produced is still somewhere on this planet. But when asked "where is all the plastic?" or "how much plastic is in the ocean or in freshwater ecosystems?", the most common answer is "we don't know." To this day, the ultimate fate of plastic pollution and its transport mechanisms in terrestrial, freshwater, and marine environments are poorly understood, both on a regional and global scale. How do we begin to tackle such an immense gap in our understanding of plastic pollution? To guide our efforts to understand the fate and transport of plastic in the environment, I suggest considering the plastic cycle-borrowing from frameworks used for carbon, nitrogen, or phosphorus (Dolman, 2019). We can use frameworks built within biogeochemical cycles to help fill in all of the unknowns within the plastic cycle. We might even consider the plastic cycle as an unknown branch of the carbon cycle, such that research on plastics ultimately contributes to our understanding of how carbon cycles in the environment.

Catholic University of the Most Holy

Conception, Chile

Reviewed by:

Karla Pozo,

Masaryk University, Czechia

Facundo Barrera,

University of Concepcion, Chile

*Correspondence:

Xia Zhu

alicexia.zhu@mail.utoronto.ca

\section{USING KNOWN FRAMEWORKS TO ELUCIDATE THE PLASTIC CYCLE}

We can adopt the terminology of biogeochemical cycles (i.e., reservoirs, sources, sinks, fluxes, and mean residence times) (Dolman, 2019) to better describe the fate of plastics in the environment. When particles of a certain substance accumulate in a place of storage, that place is deemed a "reservoir." "Sources" are reservoirs that release more particles than they accumulate. "Sinks" absorb more particles than they release. Disturbances may cause a sink to become a source, and vice versa. A "flux" is the amount of particles moving from one location to another per unit surface area per unit time. The mean residence time is the ratio of particle mass in a reservoir to the sum of either its input or output fluxes, and represents the average time a particle remains within a particular reservoir (Dolman, 2019).

In the case of carbon, major reservoirs include the terrestrial biosphere, the ocean, and fossil carbon (Figure 1a, white italicized text). Due to anthropogenic disturbance, fossil carbon-which was once a neutral reservoir-has now transformed into a carbon source. At this point, while $\mathrm{pH}$ values permit, the ocean is a carbon sink. But with decreasing alkalinity levels due to increasing greenhouse gas emissions, at some point carbon uptake into the ocean may falter and the ocean may become a carbon source (Dolman, 2019). Carbon fluxes, including ocean-terrestrial, oceanatmosphere, and terrestrial-atmosphere fluxes, link the reservoirs together (Figure 1a, yellow text). Likewise for plastic pollution, there exist reservoirs, sources, sinks, and fluxes of plastic. So far, the 
terrestrial environment is a major source of plastic due to the numerous activities-e.g., washing laundry, littering, wastewater effluent-that emit plastic pollution into the environment (Baldwin et al., 2016; Boucher and Friot, 2017; Law, 2017; Lechthaler et al., 2020). While there are many suspected reservoirs of plastic pollution in the environment, it is not well-known whether they are temporary or permanent. Plastic particles are thought to be transported via a variety of means between reservoirs such as wind currents through the atmosphere, advection in rivers and streams, waves and surface currents on the ocean surface, and subsurface currents and animal migration below the ocean surface; a name has yet to be assigned to each of these fluxes of plastic (Figure 1b, yellow text). The ocean bottom is suspected to be a sink of plastic since more plastic accumulates there than leaves. But what is very likely is that since there is no upper threshold to how much plastic the environment can hold, the majority of the environment may continue to absorb the plastic we produce indefinitely as one big sink unless we find ways to mitigate our input.

The notion of plastic having its own cycle is gaining popularity (Lecher, 2018; Bank and Hansson, 2019), but parameters have yet to be formally defined and adopted. Potentially by accident, as described above, plastic pollution researchers are already using this terminology to describe plastics. From examining the vertical "flux" of plastic to the deep ocean (Egger et al., 2020), to predicting the deep sea as a major plastic "sink" (Woodall et al., 2014), researchers have adopted these terms to described observations. To this day, the names and locations of numerous plastic reservoirs have been hypothesized from the deep ocean (Cózar et al., 2014; Woodall et al., 2014) to animals (Cózar et al., 2014) to coastlines (Hardesty et al., 2017) (Figure 1b, white italicized text), but they need to be better quantified globally-and although the ocean surface reservoir has been extensively modeled (Lebreton et al., 2012; Maximenko et al., 2012; Eriksen et al., 2014; van Sebille et al., 2015), the range of estimates can still be narrowed and improved. Likewise for plastic fluxes, much remains to be understood. It is also important to make sure that these terms are used accurately: for instance, researchers should use caution when labeling a resting place as a "sink" when it is more of a temporary storage place or reservoir, especially when there is not enough research available yet to support this claim. This is the case for animals and the ocean column, but is also true for the deep ocean and coastlines. Moving forward, we should adopt these biogeochemical cycling terms formally and use them with purpose to better quantify and characterize the reservoirs, sinks, fluxes, sources and other cycling parameters of plastic within its global cycle.

\section{PLASTIC AS AN UNKNOWN BRANCH OF THE CARBON CYCLE}

Plastic is carbon. More specifically, almost all plastic is fossil carbon locked up in polymer form (CIEL, 2015; Ellen MacArthur
Foundation, 2017; Ghaddar and Bousso, 2018; International Energy Agency, 2018). We know that fossil fuels hold 10,000 gigatonnes $(\mathrm{Gt})$ of carbon and that $9 \mathrm{Gt}$ of carbon is emitted into the atmosphere every year, but it is often forgotten that roughly $7 \mathrm{Gt}$ of that fossil carbon is now in the form of plastic (Geyer et al., 2017). In fact, since plastics account for $6 \%$ of global oil consumption (Ellen MacArthur Foundation, 2017), hypothetically if all 10,000 Gt of fossil fuels were extracted, $600 \mathrm{Gt}$ of plastic would be produced (assuming business as usual). The sheer amount of plastic produced each year places plastic on the same scale as global carbon fluxes, and thus makes plastic a fundamental part of the carbon cycleas a net flux out of the fossil carbon reservoir (Figure 1), which is currently overlooked. Plastic and greenhouse gas production are intimately connected. In fact, at every step of the plastic life cycle, from production to transportation to waste disposal, greenhouse gases are emitted (Center for International Environmental Law, 2019; Benavides et al., 2020) (Figure 1a). We spend so much time asking questions about how the use of fossil fuels increase greenhouse gas emissions and impacts our climate, but maybe now is the time to ask questions about how the increasing use of plastic is impacting our climate as well.

We can think about how plastic cycles, but we can also think about how plastic cycles carbon. Carbon moves through the cycle through various processes. Carbon is incorporated into living cells via photosynthesis, respired into the atmosphere as carbon dioxide, dissolved into the ocean as bicarbonate, buried in the deep ocean as calcium carbonate, etc. (Dolman, 2019) Since plastic is carbon, the movement of plastic through its global cycle inevitably transports carbon from one reservoir to another. Examples include the incorporation of plastic into sedimentary records (Brandon et al., 2019), the assimilation of plastic carbon into biomass (Taipale et al., 2019), and the suspension and deposition of airborne plastic particles as part of atmospheric fluxes (Brahney et al., 2020) (Figure 1b, boxed text). Interestingly, plastic settling to the bottom of the ocean is also a flux of carbon to the bottom, thereby working in synergy with the biological pump. Furthermore, inorganic carbon continuously leaches from plastic (Romera-Castillo et al., 2018) and plastic may release greenhouse gases as a result of UV exposure (Royer et al., 2018) or open burning (Mari et al., 2019). In all of these cases, the carbon within plastic is being chemically transformed or transported to different places; plastic is a vector of carbon. Consequently, it is crucial to better understand just how much carbon is moving between reservoirs in the form of plastic, and how plastic contributes to carbon cycling overall.

In this discussion of plastic cycling and carbon cycling, there is a common theme of anthropogenic interference. While the carbon cycle has become altered as a result of anthropogenic activities, anthropogenic activities have catapulted the existence of the entire global plastic cycle itself. Since we have influenced these cycles, it is crucial that we better understand the mechanisms behind how they work and consistently evaluate the impact of such changes on these cycles. 


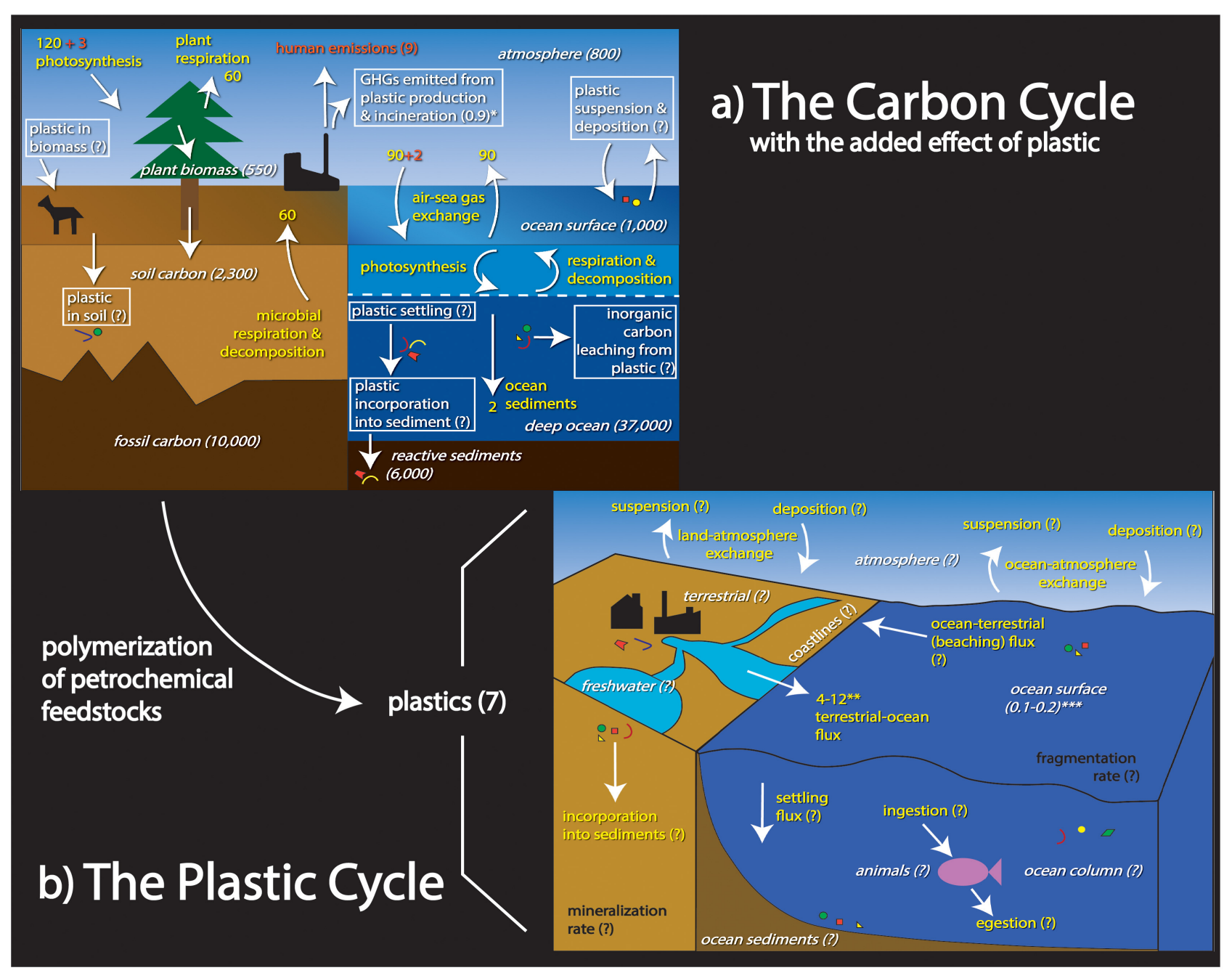

FIGURE 1 | (a) The carbon cycle (redrawn using content from NASA Earth Observatory) with plastic production shown as a net flux out of fossil carbon. Carbon reservoirs are italicized in white (GT), natural fluxes are in yellow (GT/yr), and anthropogenic fluxes are in red (GT/yr). Boxes show how plastic may contribute to additional carbon movement. (b) The plastic cycle with major parameters shown. Reservoirs are italicized in white (megatonnes, MT), fluxes are in yellow (MT/yr), and important rates are shown in black (MT/yr). ${ }^{\star} 0.9$ GT of greenhouse gases (GHGs) were estimated to have been emitted from plastic production and incineration in 2019 (Center for International Environmental Law, 2019). ${ }^{* *} 4-12$ MT plastic/year is input from coastal regions into the ocean; this estimate is for the year 2010 and is taken from Jambeck et al. (2015). ${ }^{\star \star \star} 0.1-0.2$ MT plastic is for microplastics only and taken from van Sebille et al. (2015).

\section{FILLING IN THE UNKNOWNS}

In the words of Thompson et al. (2004): "Lost at sea, where is all the plastic?". Using a known framework, maybe we can begin to tackle this question globally. To better understand the plastic cycle, we need to put values to various components of the plastic cycle both locally and globally. How much plastic resides in each reservoir (Figure 1b, white italicized text)? What are the fluxes of plastic in the atmosphere, in the ocean, and on land (Figure 1b, yellow text)? What are the fragmentation, degradation, and mineralization rates of plastic in various environments (Figure 1b, black text)? As we attempt to answer these questions, we also need to take into consideration how the magnitudes of the reservoirs and fluxes vary through space and time. Furthermore, we should think deeply about the interconnections between plastic and the carbon cycle and consider plastic within the bigger picture of the carbon cycle, by asking ourselves the following questions: how much carbon is moved by plastic locally and globally (Figure 1a, boxed text)? This must include through the atmosphere, terrestrial soils, aquatic environments, and via biotic transport. I believe both plastic cycling itself, as well as the contribution of plastic to carbon cycling, need to be better understood to help us assess the impact that plastic has on our lives and our planet. Now, we must dedicate our time to filling in the gaps in these cycles (Figure 1).

\section{AUTHOR CONTRIBUTIONS}

The author confirms being the sole contributor of this work and has approved it for publication. 


\section{FUNDING}

XZ was supported by the Vanier Canada Graduate Scholarship from the Natural Sciences and Engineering Research Council of the Government of Canada.

\section{REFERENCES}

Baldwin, A. K., Corsi, S. R., and Mason, S. A. (2016). Plastic debris in 29 great lakes tributaries: relations to watershed attributes and hydrology. Environ. Sci. Technol. 50, 10377-10385. doi: 10.1021/acs.est.6b02917

Bank, M. S., and Hansson, S. V. (2019). The plastic cycle: a novel and holistic paradigm for the anthropocene. Environ. Sci. Technol. 53, 7177-7179. doi: 10.1021/acs.est.9b02942

Benavides, P. T., Lee, U., and Zarè-Mehrjerdi, O. (2020). Life cycle greenhouse gas emissions and energy use of polylactic acid, bio-derived polyethylene, and fossil-derived polyethylene. J. Clean. Prod. 277:124010. doi: 10.1016/j.jclepro.2020.124010

Boucher, J., and Friot, D. (2017). International Union for Conservation of Nature: a Global Evaluation of Sources Primary Microplastics in the Oceans. Available online at: https://www.iucn.org/content/primary-microplastics-oceans

Brahney, J., Hallerud, M., Heim, E., Hahnenberger, M., and Sukumaran, S. (2020). Plastic rain in protected areas of the United States. Science 368, 1257-1260. doi: 10.1126/science.aaz5819

Brandon, J. A., Jones, W., and Ohman, M. D. (2019). Multidecadal increase in plastic particles in coastal ocean sediments. Sci. Adv. 5:eaax0587. doi: $10.1126 /$ sciadv.aax0587

Carpenter, E. J., and Smith, K. L. (1972). Plastics on the Sargasso sea surface. Science 175, 1240-1241. doi: 10.1126/science.175.4027.1240

Center for International Environmental Law (2019). Plastic \& Climate, The Hidden Costs of a Plastic Planet. Available online at: https://www.ciel.org/wp-content/ uploads/2019/05/Plastic-and-Climate-FINAL-2019.pdf

CIEL (2015). Center for International Environmental Law. Fossil Fuels and Plastic. Available online at: https://www.ciel.org/issue/fossil-fuels-plastic/

Cózar, A., Echevarría, F., González-Gordillo, J. I., Irigoien, X., Úbeda, B., Hernández-León, S., et al. (2014). Plastic debris in the open ocean. Proc. Natl. Acad. Sci. U. S. A. 111, 10239-10244. doi: 10.1073/pnas.1314705111

Dolman, H. (2019). Biogeochemical Cycles and Climate. Oxford Scholarship. Oxford. doi: 10.1093/oso/9780198779308.001.0001

Egger, M., Sulu-Gambari, F., and Lebreton, L. (2020). First evidence of plastic fallout from the North Pacific Garbage Patch. Sci. Rep. 10:7495. doi: 10.1038/s41598-020-64465-8

Ellen MacArthur Foundation (2017). The New Plastics Economy: Rethinking the Future of Plastics. Available online at: https://www.ellenmacarthurfoundation. org/publications/the-new-plastics-economy-rethinking-the-future- ofplastics

Eriksen, M., Lebreton, L. C. M., Carson, H. S., Thiel, M., Moore, C. J., Borerro, J. C., et al. (2014). Plastic pollution in the world's oceans : more than 5 trillion plastic pieces weighing over 250,000 tons afloat at sea. PLoS ONE. 9:e111913. doi: 10.1371/journal.pone.0111913

Free, C. M., Jensen, O. P., Mason, S. A., Eriksen, M., Williamson, N. J., Boldgiv, B. (2014). High-levels of microplastic pollution in a large, remote, mountain lake. Mar. Pollut. Bull. 85, 156-163. doi: 10.1016/j.marpolbul.2014. 06.001

Geyer, R., Jambeck, J. R., and Law, K. L. (2017). Production, use, and fate of all plastics ever made. Sci. Adv. 3:e1700782. doi: 10.1126/sciadv.1700782

Ghaddar, A., and Bousso, R. (2018). Rising use of plastics to drive oil demand to 2050: IEA - Reuters. Available online at: https://www.reuters.com/article/uspetrochemicals-iea/rising-use- of-plastics-to-drive-oil-demand-to-2050-ieaidUSKCN1ME2QD

Hardesty, B. D., Lawson, T., van der Velde, T., Lansdell, M., and Wilcox, C. (2017). Estimating quantities and sources of marine debris at a continental scale. Front. Ecol. Environ. 15, 18-25. doi: 10.1002/fee.1447

International Energy Agency (2018). The Future of Petrochemicals Towards more sustainable plastics and fertilisers Together Secure Sustainable Executive summary. Available online at: www.iea.org/t\&c/

\section{ACKNOWLEDGMENTS}

Author thank L. Werbowski, S. Athey for comments on the figure. Author thank C. Rochman for comments on the manuscript.

Jambeck, J. R., Geyer, R., Wilcox, C., Siegler, T. R., Perryman, M., Andrady, A., et al. (2015). Plastic waste inputs from land into the ocean. Science 347, 768-771. doi: $10.1126 /$ science. 1260352

Jamieson, A. J., Brooks, L. S. R., Reid, W. D. K., Piertney, S. B., Narayanaswamy, B. E., and Linley, T. D. (2019). Microplastics and synthetic particles ingested by deep-sea amphipods in six of the deepest marine ecosystems on Earth. R. Soc. Open Sci. 6:180667. doi: 10.1098/rsos. 180667

Law, K. L. (2017). Plastics in the Marine environment. Ann. Rev. Mar. Sci. 9, 205-229. doi: 10.1146/annurev-marine-010816-060409

Lebreton, L. C., Greer, S. D., and Borrero, J. C. (2012). Numerical modelling of floating debris in the world's oceans. Mar. Pollut. Bull. 64, 653-661. doi: 10.1016/j.marpolbul.2011.10.027

Lecher, A. L. (2018). Piecing together the plastic cycle. Nat. Geosci. 11:153. doi: 10.1038/s41561-018-0077-9

Lechthaler, S., Waldschläger, K., Stauch, G., and Schüttrumpf, H. (2020). The way of macroplastic through the environment. Environments 7:73. doi: 10.3390/environments7100073

Liu, K., Wu, T., Wang, X., Song, Z., Zong, C., Wei, N., et al. (2019). Consistent Transport of Terrestrial Microplastics to the Ocean through Atmosphere. Environ. Sci. Technol. 53, 10612-10619. doi: 10.1021/acs.est.9b03427

Mari, W., Rich, G., Joanne, G., Elisabeth, W., Zoe, L., and Patrick, S. (2019). No Time to Waste: Tackling the Plastic Pollution Crisis Before it's Too Late. Available online at: https://opendocs.ids.ac.uk/opendocs/handle/20.500.12413/14490

Maximenko, N., Hafner, J., and Niiler, P. (2012). Pathways of marine debris derived from trajectories of Lagrangian drifters. Mar. Pollut. Bull. 65, 51-62. doi: 10.1016/j.marpolbul.2011.04.016

Moore, C. J., Moore, S. L., Leecaster, M. K., and Weisberg, S. B. (2001). A comparison of plastic and plankton in the North Pacific Central Gyre. Mar. Pollut. Bull. 42, 1297-1300. doi: 10.1016/S0025-326X(01)00114-X

Romera-Castillo, C., Pinto, M., Langer, T. M., Álvarez-Salgado, X. A., and Herndl, G. J. (2018). Dissolved organic carbon leaching from plastics stimulates microbial activity in the ocean. Nat. Commun. 9, 1-7. doi: 10.1038/s41467-018-03798-5

Royer, S.-J., Ferrón, S., Wilson, S. T., and Karl, D. M. (2018). Production of methane and ethylene from plastic in the environment. PLoS ONE 13:e0200574. doi: 10.1371/journal.pone.0200574

Taipale, S. J., Peltomaa, E., Kukkonen, J. V. K., Kainz, M. J., Kautonen, p., and Tiirola, M. (2019). Tracing the fate of microplastic carbon in the aquatic food web by compound-specific isotope analysis. Sci. Rep. 9, 1-15. doi: 10.1038/s41598-019-55990-2

Thompson, R. C., Olsen,Y., Mitchell, R. P., Davis, A., Rowland, S. J., John, A. W. G., et al. (2004). Lost at sea: where is all the plastic? Science 304, 838-839. doi: 10.1126/science.1094559

van Sebille, E., Wilcox, C., Lebreton, L., Maximenko, N., Hardesty, B. D., van Franeker, J. A., et al. (2015). A global inventory of small floating plastic debris. Environ. Res. Lett. 10:124006. doi: 10.1088/1748-9326/10/12/124006

Woodall, L. C., Sanchez-Vidal, A., Canals, M., Paterson, G. L. J., Coppock, R., Sleight, V., et al. (2014). The deep sea is a major sink for microplastic debris. R. Soc. Open Sci. 1:140317. doi: 10.1098/rsos.140317

Conflict of Interest: The author declares that the research was conducted in the absence of any commercial or financial relationships that could be construed as a potential conflict of interest.

Copyright (c) 2021 Zhu. This is an open-access article distributed under the terms of the Creative Commons Attribution License (CC BY). The use, distribution or reproduction in other forums is permitted, provided the original author(s) and the copyright owner(s) are credited and that the original publication in this journal is cited, in accordance with accepted academic practice. No use, distribution or reproduction is permitted which does not comply with these terms. 